\title{
COSTA RICA COMO EXPULSOR DE PERSONAS MIGRANTES: UNA LECTURA DESDE LA ECONOMÍA POLIITICA ${ }^{1}$
}

\author{
COSTA RICA AS A SOURCE OF EMIGRANTS: A READING FROM A POLITICAL \\ ECONOMY APPROACH
}

\section{Gustavo Gatica López²}

\begin{abstract}
Resumen
Los datos disponibles permiten observar un incremento de las migraciones internacionales desde Costa Rica, principalmente hacia Estados Unidos. A partir de los datos de dos encuestas aplicadas a personas potenciales migrantes y a hogares con familiares en el extranjero, el presente trabajo se acerca a comprender las razones de estos desplazamientos. Asimismo, se identifican algunos impactos socioeconómicos en cuatro cantones expulsores de población. Desde el enfoque de la economía política del desarrollo, se discute el marco desde el cual pueden comprenderse de mejor forma estos desplazamientos. Por otra parte, las transformaciones de la matriz productiva y de empleo seguida por Costa Rica en las últimas tres décadas así como la forma de inserción a la economía internacional llevada a cabo por el país, son dos factores estructurales que inciden $y$ se relacionan con los desplazamientos de personas que se estudian en este trabajo.
\end{abstract}

Palabras claves: migración; desarrollo; remesas familiares

Doi: http://dx.doi.org/10.15359/eys.22-51.3

Fecha de recepción: 18-11-2016. Fechas de reenvíos: 22-11-2016, 30-11-2016, 05-12-2016, 11-01-2017, 06-03-2017, 18-03-2017, 31-03-2017. Fecha de aceptación: 03-04-2017. Fecha de publicación: 10-04-2017.

1 El artículo es un resultado del proyecto de investigación: Migraciones internacionales desde Costa Rica, aproximación a partir de dos estudios de caso en los cantones de Pérez Zeledón, Dota, Tarrazú y León Cortés, del Centro de Investigación en Cultura y Desarrollo (CICDE) de la Universidad Estatal a Distancia (UNED) de Costa Rica, coordinado por el autor de este artículo.

${ }^{2}$ Guatemalteco. Investigador del Centro de Investigación en Cultura y Desarrollo (CICDE) de la Universidad Estatal a Distancia (UNED), Costa Rica. Correo electrónico: ggatica@uned.ac.cr

Gustavo Gatica López

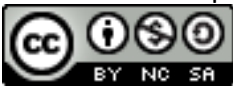

Revista Economía y Sociedad by Universidad Nacional is licensed under a CreativeCommons Reconocimiento-NoComercial- 


\begin{abstract}
Available data shows an increase in international migration departing from Costa Rica, mainly to the United States. Based on the data obtained from two surveys conducted with potential emigrants and families with members living abroad, this paper is aimed at understanding their reasons for emigrating. In addition, some socio-economic impacts in four suburbs with high rates of emigration are identified. From a political economy approach, the most appropriate framework to better understand these emigration cases is discussed. Moreover, the transformation of the employment and productive matrix followed by Costa Rica during the last three decades, as well as the country's form of insertion into the international economy are two structural factors strongly linked to the emigration of the subjects studied in this paper.
\end{abstract}

Keywords: migration; development; family remittances

\title{
Introducción
}

Este artículo analiza la migración de costarricenses hacia Estados Unidos a partir del estudio en cuatro cantones emisores netos de población migrante (Pérez Zeledón, Dota, Tarrazú y León Cortés). En estos cantones se recolectó información de hogares con familiares en el extranjero que a la vez, reciben remesas familiares-, así como de personas que manifestaron su interés en emigrar. Además de lo anterior, hubo otros aspectos que motivaron la realización de la investigación:

- Estos cantones se ubican fuera del Gran Área Metropolitana de Costa Rica y su estructura de empleo gira en torno al sector primario. Siguiendo el concepto de heterogeneidad estructural (Rodríguez, 1984 y 1998), se distinguirían de los cantones que se ubican en el Gran Área Metropolitana (cantones del centro), que concentran la mayor parte del empleo en los sectores industriales y de servicios.

- Estos cantones han tenido históricamente una fuerte vinculación a la producción del café. Estas actividades demandan intensivamente mano de obra menos calificada, con menor productividad y menores salarios en comparación con otras actividades ocupacionales que pueden requerir mayor calificación o especialización. Los cantones de Pérez Zeledón y los de la Zona de Los Santos, se ubicarían como cantones periféricos.

- Por otra parte, el interés de estudiar estos cantones se asocia a observar cómo, a partir de la apuesta del país por un tipo de inserción a la economía internacional, se prioriza la atracción de inversión extranjera directa para estimular actividades económicas

2

Gustavo Gatica López

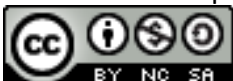

Revista Economía y Sociedad by Universidad Nacional is licensed under a CreativeCommons Reconocimiento-NoComercial- 
vinculadas a la exportación (manufactura tecnológica, soporte y servicios técnicos, entre otros) en detrimento de actividades agrícolas que se quedan rezagadas respecto de aquellas por las que se prioriza y que cuentan con un conjunto de políticas de fomento bien delineadas, con un cierto nivel de consistencia, con apoyo institucional y financiero.

El artículo se estructura en cuatro apartados. En el primero, se desarrolla el marco teórico a partir del cual se interpretan los cambios y transformaciones de estos movimientos migratorios. Un segundo apartado describe la evolución de las migraciones internacionales desde Centroamérica y, en particular, desde Costa Rica. En el tercer apartado se describe la metodología y se muestran los resultados del trabajo de campo. En un último apartado se plantean algunas conclusiones.

\section{Migraciones internacionales, una lectura desde la economía política del desarrollo}

Los estudios sobre migraciones internacionales han sido generosos en la utilización de distintos marcos teóricos. En particular, la teoría económica en su vertiente neoclásica ha proporcionado criterios de análisis que han dominado buena parte de la literatura sobre migraciones.

El enfoque neoclásico, en su explicación convencional, analiza la migración dentro de las dinámicas de los movimientos internacionales de factores: trabajo y capital. Los supuestos teóricos de este enfoque parten de un modelo con dos países; suponen que el trabajo es un factor homogéneo y móvil en ambos; por tanto, este debe moverse de áreas de abundancia y salarios más bajos a áreas de escasez y de salarios más altos (Ray, 2002). Este movimiento del factor trabajo hace que los salarios aumenten en el área de emigración y bajen en el área de inmigración. En ausencia de costos de traslado, el factor trabajo continua moviéndose hasta que los salarios sean iguales en las dos regiones (Appleyard y Field, 2003). Bajo los supuestos de este enfoque, en el largo plazo asistiríamos a una convergencia salarial que daría como resultado una estabilización de los desplazamientos de las personas trabajadoras migrantes.

La interpretación de las migraciones desde este enfoque asume la migración internacional como parte de un gran mercado. En este, los factores se desplazan a donde obtengan mayores beneficios. La decisión de migrar no está determinada por las condiciones sociohistóricas de los países expulsores, sino por la "decisión racional" que toma un individuo (Todaro, 1969) a partir de la ponderación de las potenciales ganancias y beneficios que esperaría tener de forma individual. Este planteamiento supone que la persona que va a migrar tiene información completa (óptima) de los riesgos del viaje o de las dificultades de inserción en el mercado laboral del país receptor.

Asimismo, este enfoque asigna un papel relevante al mercado, dado que determina la direccionalidad de los movimientos migratorios. Asumiendo entonces que el mercado es el mecanismo que mejor asigna los recursos y que el trabajo es solo un factor de producción, la migración deviene en algo consustancial y necesario a los mercados de trabajo que se encargan 
de asignar eficientemente los factores según la demanda existente y "el mejor uso posible". Este enfoque ve desplegada otra línea argumental que propone un "aprovechamiento productivo" de las remesas familiares, dado su "potencial catalizador de desarrollo". Diversos estudios proponen ver la migración como una variable independiente del desarrollo, a los migrantes como los sujetos y a las remesas como el instrumento de desarrollo, con lo cual se coloca la migración como una alternativa de financiamiento para el desarrollo local y territorial (Orozco y Yansura, 2013; Orozco, 2012). En el ámbito costarricense, esta tesis ha sido desarrollada por Céspedes, Monge y Vargas (2010), quienes han sugerido que las remesas son "parte de la solución" y una "oportunidad para el desarrollo". Más aún, según estos autores, "la migración ocurre en el sur porque esa es la mejor decisión que toman los emigrantes en conjunto con su familia" (2010, pp. 22-23).

Ahora bien, los alcances interpretativos de la corriente principal resultan limitados, entre otras razones, por las siguientes:

- Los supuestos teóricos aplicados al análisis de la migración corresponden a patrones ideales que poco se relacionan con lo que sucede en la realidad. La reducción del trabajo humano a la categoría de factor de producción que se desplaza mecánicamente de regiones o países con bajos salarios a otras con altos salarios asume que hay una completa o plena movilidad "de factores". Las restricciones a la migración laboral que se observan actualmente en el corredor migratorio Centroamérica-México-Estados Unidos, confirman que ello no es así.

- Anula el marco socio-histórico desde el cual se configuran objetivamente los desplazamientos de personas. Este enfoque centra su fuerza argumentativa en la decisión individual o las racionalidades individuales como factor explicativo de las migraciones "enfoque microsocial"- (Márquez, 2010) y desplaza los factores estructurales y estructurantes vinculados al desarrollo desigual (Márquez, 2010; Delgado y Márquez, 2009).

- El enfoque en cuestión promueve una visión romántica a través de la cual la migración y las remesas son una variable independiente que promueve el desarrollo. Este planteamiento ubica a las personas migrantes como los sujetos y a las remesas como el instrumento que apalanca el desarrollo (Márquez, 2010; Delgado y Márquez, 2009). Esta interpretación ve la migración como algo positivo, donde los grandes beneficiados son los países expulsores de personas y receptores de remesas familiares. Además de las divisas que genera la migración, se resalta la transferencia de conocimientos y de capacidades a las que da lugar la migración. Esta visión no toma en consideración aspectos como los costos económicos impuestos a los países expulsores por la formación y preparación de quienes se van, lo que Amin llamó, en su momento, la transferencia de valor oculto de la

4

Gustavo Gatica López

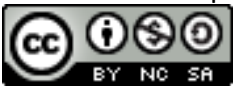

Revista Economía y Sociedad by Universidad Nacional is licensed under a CreativeCommons Reconocimiento-NoComercial- 
periferia al centro (1981); el despoblamiento o la transferencia del bono demográfico (Márquez, 2010, p. 70), la crónica dependencia de las remesas; y la pérdida de su población como principal valor que tiene un país.

El enfoque teórico bajo el que elaboramos el presente artículo se inscribe dentro de la economía política del desarrollo.

\section{Desarrollo desigual, globalización y migraciones}

Durante la segunda parte del siglo pasado, América Latina fue territorio fértil para las discusiones sobre la noción de "desarrollo". Dos perspectivas ofrecieron contribuciones a las discusiones de esos años. Por una parte, la influencia de Raúl Prebisch y la CEPAL promovieron un enfoque estructuralista que resaltó la heterogeneidad de las economías y estructuras productivas latinoamericanas, el deterioro de los términos de intercambio y los desequilibrios externos (Rodríguez, 1984 y 1998). Este enfoque promovió, durante las décadas de los años cincuentasetenta del siglo pasado, un mayor intervencionismo del Estado dentro de los marcos de la economía convencional, a decir de Rodríguez (1984). Por otra parte, fueron significativos los aportes de la teoría de la dependencia; esta planteó la relación desigual entre los países bajo una dinámica metrópoli-satélite. El núcleo analítico giraba en torno a "concebir que el subdesarrollo no es una fase previa al desarrollo, sino que es su producto, y en buena medida es el resultado del colonialismo y del imperialismo" (Gudynas, 2012, p. 24).

La virtud de ambas perspectivas radicó en establecer con claridad, en primer lugar, los factores estructurales que históricamente configuraron la heterogeneidad productiva y ocupacional en América Latina. Esta perspectiva señaló las limitaciones de la especialización en la producción de materias primas y la alta concentración del sector primario en la estructura ocupacional y de exportaciones, lo que Rodríguez (1984) denominó la "estructura productiva especializada y heterogénea de la periferia", frente a la "diversificada y homogénea" de la estructura productiva de los centros.

En segundo lugar, que este tipo de especialización condicionaba la forma de integración de los países -periféricos- a la economía internacional y a las cadenas globales de producción, las cuales demandaban intensamente materias primas que eran procesadas y comercializadas en todo el mundo. La inserción de los países periféricos, respecto de los países centrales, ocurría -y sigue ocurriendo- en condiciones de desigualdad y asimetría.

En términos metodológicos, ambas perspectivas subrayaron que una de las formas de inserción desigual -a lo que hoy llamaríamos la economía internacional- fue a través de la provisión intensiva de materias primas que eran procesadas en los países desarrollados. Lo anterior ofrece una clave interpretativa para comprender cómo los países periféricos se integran hoy a la economía y a los procesos globales de producción capitalista: a través de la exportación/expulsión 
de personas que contribuyen con su fuerza de trabajo a nutrir las dinámicas de acumulación patrimonial. La migración desde los países periféricos a los países centrales es una forma de integración desigual a los procesos globales de producción.

A Wallerstein se le debe el amplio uso de la noción sistema-mundo. El "sistema mundo" que sugiere Wallerstein es una zona espacio-temporal que atraviesa múltiples unidades políticas y culturales y que representa una zona integrada de actividad e instituciones que obedecen a ciertas reglas sistémicas (2006). En tanto que:

(...) la economía mundo designa una gran zona geográfica dentro de la cual existe una división del trabajo y por lo tanto un intercambio significativo de bienes básicos o esenciales, así como un flujo de capital y trabajo. Una característica definitoria de una economía-mundo es que no está limitada por una estructura política unitaria. (Wallerstein, 2006, p. 38)

A partir de la categoría de sistema-mundo, podemos colocar la migración no como variable independiente, sino como una variable dependiente, parte de un sistema: el sistema mundo /economía mundo.

Introducir esta noción despliega al menos dos posibilidades. La primera es que, de acuerdo con Wallerstein, se sustituye la unidad de análisis, que había sido el Estado nacional, por la unidad de análisis "sistema mundo". Con la segunda, se distingue que al referirse a "sistemas mundo" se hace referencia no a sistemas, economías o imperios de todo el mundo, sino a sistemas, economías e imperios que son un mundo. Es decir, a la forma en la que operan y se llevan a cabo sus dinámicas internas.

La utilización de la noción "sistema mundo" permite comprender que, al interior de un sistema económico, sus dinámicas internas -producción, demanda de bienes intermedios y tecnología, de distribución, de comercialización y de distribución de excedentes- operan y funcionan como un mundo, con una articulación y estructuración que no son antojadizas. Tales dinámicas internas requieren de la división del trabajo y de la provisión de bienes primarios (en reiterados casos bajo dinámicas extractivistas de sobreexplotación de recursos naturales), con una dotación de tecnologías militares, informáticas y de salud (lideradas por los países desarrollados) que acentúan y refuerzan los núcleos de acumulación capitalista.

Un marco global como este, y que se organiza como un "sistema mundo", determina y ordena las distintas dinámicas que a su interior acontecen; y la migración no escapa a ello. A diferencia del enfoque convencional, el cual postula que la migración es un fenómeno o hecho autónomo -que se explica en buena parte por la decisión individual de las personas que migran-, desde la perspectiva de la economía política del desarrollo, la migración es y forma parte de un sistema

6 
mayor: el sistema-economía-mundo. Lo que caracteriza a este es la delimitación espaciotemporal de una zona que integra actividades e instituciones, las cuales obedecen a ciertas reglas sistémicas (no limitadas por una estructura política unitaria), que requiere la división del trabajo y un gran mercado de bienes, capital y trabajo. Así las cosas, la migración no puede entenderse como un hecho autónomo, menos aún, al margen de reglas sistémicas: debe comprenderse en relación con este marco.

Autores como Delgado y Márquez (2007 y 2009) han señalado cómo las dinámicas constitutivas de la globalización, a saber, la reconfiguración de las cadenas globales de producción, la formación de mercados globales, la intensificación de las redes transnacionales y translocales (Sassen, 2003), la internacionalización de las finanzas (Delgado, Márquez y Rodríguez, 2009) y las nuevas formas de capitalismo patrimonial (Piketty, 2014), no solo han contribuido a fortalecer los mecanismos de concentración de la riqueza, sino que también han impactado en el incremento de las migraciones en el mundo (Castles, 2005). Paralelamente se intensifican los mecanismos de expulsión de mano de obra barata desde los países emisores, lo que favorece una inserción basada en la explotación laboral en los países receptores (Delgado, Márquez y Rodríguez, 2009; Castles, 2005).

Delgado y Márquez (2007 y 2009), así como Márquez (2010), han propuesto que un enfoque pertinente es el de la economía política del desarrollo, en tanto "considera que la migración internacional deviene de los problemas del desarrollo y que el fenómeno migratorio no puede estudiarse en sí mismo para dilucidar sus causas y efectos más profundos" (2007, p. 11). Este enfoque es el que se sigue en este artículo.

\section{Ni son pocos los que se van, ni los impactos de la emigración son marginales}

La emigración de costarricenses no es nueva, y las personas que se van no son pocas. Para 1970 el Censo de Población de los Estados Unidos de Norteamérica registró un total de 16.691 personas costarricenses viviendo en ese país, mientras que para el año 2010, esa cantidad se incrementó a 126.418. No solo se incrementa la cantidad de personas expulsadas desde Costa Rica, también aumentan las remesas familiares.

La Figura 1 ilustra el comportamiento de esta variable entre los años 2007-2015 y lo compara con el dato de Inversión Extranjera Directa (IED) para esos mismos años. Nótese que entre los años 2008-2009, los años en los que la crisis económica mundial fue más intensa, la caída de la IED fue de $\$ 899,2$ millones, en tanto que la caída de las remesas fue de $\$ 95,3$ millones.

Además de incrementar las divisas que recibe el país, las remesas familiares tienen al menos dos impactos significativos. En primer lugar, incrementan el ingreso disponible de los hogares que las reciben. En segundo lugar, a través del consumo de los hogares, hay un aporte fiscal a la hacienda pública. 


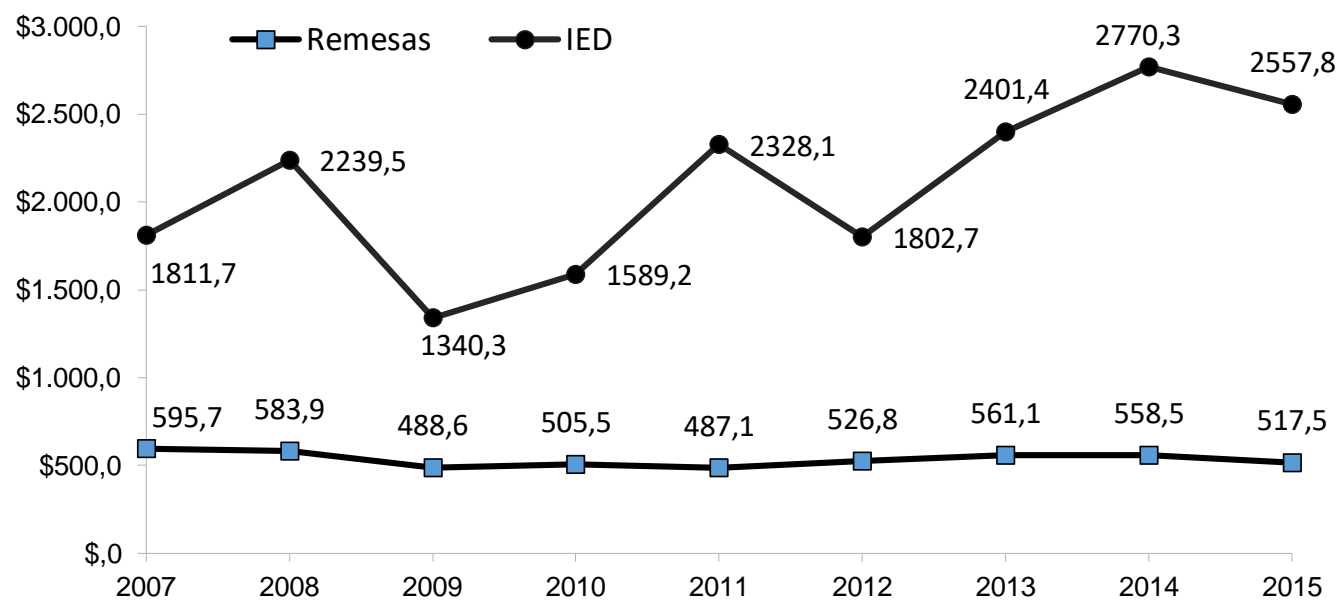

Figura 1. Costa Rica: remesas familiares e inversión extranjera directa (20072015) en millones de dólares. Fuente: elaboración propia con indicadores económicos del Banco Central de Costa Rica ${ }^{3}$.

¿Qué potencial impacto fiscal pueden tener las remesas familiares en Costa Rica? A partir del análisis de un impuesto específico puede medirse dicho impacto. Se tomará el impuesto de ventas, que es equiparable al impuesto al valor agregado utilizado en otros países. Las fuentes de información utilizadas son los datos sobre consumo de los hogares que provee la Encuesta Nacional de Ingresos y Gastos de los Hogares (ENIGH, 2014b) del Instituto Nacional de Estadísticas y Censos y los datos sobre recaudación tributaria del Ministerio de Hacienda.

La ENIGH ( $\underline{2014 b})$ estimó el gasto total, promedio y porcentaje que realizan los hogares. Los gastos corrientes de consumo que realizan los hogares representan en términos porcentuales el $56,5 \%$. La encuesta identificó una serie de gastos realizados por los hogares que están exentos del pago del impuesto de ventas. Entre estos se incluyen los gastos en educación, que corresponden a un 2,9\%; vivienda, agua, electricidad, gas y otros combustibles $(5,9 \%)$; y salud $(2,6 \%)$. Al ajustar el gasto corriente de los hogares, sujeto al pago de impuesto de ventas en términos porcentuales es de 45,1\%. Dicho con otras palabras, de cada 100 colones, los hogares tendrían un consumo de $45,1 \%$ sujeto al pago de impuesto de ventas. Por otra parte, se asume que la estructura de gastos de los hogares no tendría variaciones significativas entre aquellos que reciben remesas y los que no las reciben.

Sobre la base del $45,1 \%$ del gasto corriente que realizan los hogares, se estima un cálculo acerca de la potencial contribución, a través del Impuesto General de Ventas (IGV), a los ingresos fiscales de Costa Rica, que tendrían su origen en las remesas familiares para el año de referencia 2013, que fue el año de recolección de datos de la Encuesta de Ingresos y Gastos. Teniendo el dato del

${ }^{3}$ Los datos consignados en la Figura 1, pueden ser consultados en el Banco Central de Costa Rica (2017a, 2017b). 8 
porcentaje de gasto de consumo gravable, se calculó el potencial recaudatorio a partir de los datos oficiales de recaudación registrados por el Ministerio de Hacienda para el año 2013, teniendo a la vista el valor total de las remesas familiares recibidas en el país, expresadas en colones al tipo de cambio de julio del año en referencia, como se observa en la Tabla 1.

Para dicho año, el Ministerio de Hacienda de Costa Rica estimó que el ingreso por el IGV fue de ¿1.176.744,8 millones. Los datos para el cálculo se presentan en la Tabla 1. El potencial aporte de las remesas familiares a través de la recaudación del Impuesto General de Ventas alcanzaría los \$16.597.671,237 millones, esto es el equivalente, al tipo de cambio de julio 2013 , de $\$ 32,9$ millones.

\section{Tabla 1.}

Costa Rica: Remesas familiares y potencial aporte a la recaudación fiscal * a través del Impuesto General de Ventas (IGV), en millones de colones corrientes, durante el año 2013. Tipo de cambio de julio 2013.

\begin{tabular}{|c|c|c|}
\hline \multirow{2}{*}{ Indicador } & \multicolumn{2}{|l|}{2013} \\
\hline & Colones & $\$$ \\
\hline Ingresos tributarios por IGV & ¿845.004.190 & $\$ 1.674 .834,38$ \\
\hline Remesas totales en dólares y colones & c366.894.216.000 & $\$ 727.200 .000$ \\
\hline Tipo de cambio de referencia & c 504,53 & \\
\hline Estimación de consumo de los hogares (en \%) & $43,9 \%$ & \\
\hline $\begin{array}{l}\text { Estimación de consumo de los hogares receptores de remesas } \\
\text { en términos absolutos }\end{array}$ & C161.066.560.824 & $\$ 319.240 .800,00$ \\
\hline Porcentaje de impuesto general de ventas & $13,0 \%$ & \\
\hline $\begin{array}{l}\text { Potencial aporte a los ingresos fiscales por IGV en términos } \\
\text { absolutos }\end{array}$ & ¿20.938.652.907 & $\$ 41.501 .304,00$ \\
\hline $\begin{array}{l}\text { Aporte potencial de las remesas familiares a la recaudación } \\
\text { total del IGV en términos relativos }\end{array}$ & $2,48 \%$ & $2,48 \%$ \\
\hline Aporte de las remesas al PIB durante el año 2013 & $1,38 \%$ & \\
\hline
\end{tabular}

Los datos de la Tabla 1 muestran que las remesas familiares hacen una silenciosa pero efectiva contribución a la recaudación fiscal del país. Ello a pesar de que Costa Rica tradicionalmente no se ve como un país expulsor de personas migrantes. 
Trabajo de campo: aspectos metodológicos, definición y tamaño de la población de interés ${ }^{4}$

Se seleccionaron cuatro cantones que, de acuerdo con el XI Censo de Población (INEC, 2012), tenían un porcentaje de hogares con familiares en el extranjero que duplicaba el promedio nacional (3,5\%). Estos son: Pérez Zeledón (8,16\%), Dota (7,95\%), Tarrazú (9,39\%) y León Cortes $(7,20 \%)$, todos de la provincia de San José.

Según los objetivos del estudio, la población de interés se conformó por los hogares individuales en los cuatro cantones seleccionados que tienen al menos un miembro del hogar en el extranjero. La estimación de estos hogares tomó como base los resultados del Censo Nacional de Población y Vivienda (INEC, 2012). El total de hogares en los cuatro cantones de interés era de 48.932, de los cuales 4.012 tenían miembros en el extranjero. En términos porcentuales ello representa aproximadamente un $8 \%$ de hogares en dicha condición (Tabla 2).

\section{Tabla 2.}

Costa Rica: número de hogares con miembros en el extranjero, tamaño de la muestra en los cantones seleccionados.

\begin{tabular}{lccccc}
\hline \multicolumn{1}{c}{ Cantón } & Total, hogares & $\begin{array}{c}\text { Hogares con } \\
\text { emigrantes }\end{array}$ & \% de hogares & $\begin{array}{c}\text { \% hogares del } \\
\text { total }\end{array}$ & $\begin{array}{c}\text { Distribución de } \\
\text { la muestra }\end{array}$ \\
\hline Tarrazú & 4.632 & 435 & 0,90 & 10,86 & 40 \\
Dota & 1.988 & 158 & 0,80 & 3,94 & 30 \\
León Cortés & 3.431 & 241 & 0,80 & 6,02 & 30 \\
Pérez Zeledón & 38.881 & 3.172 & 0,70 & 79,18 & 225 \\
\hline Totales & $\mathbf{4 8 . 9 3 2}$ & $\mathbf{4 . 0 0 6}$ & $\mathbf{0 , 8 0}$ & $\mathbf{1 0 0 , 0 0}$ & $\mathbf{3 2 5}$ \\
\hline
\end{tabular}

Fuente: elaboración propia con base en datos del Censo 2011 y cálculos propios.

Los mapas de las áreas geográficas correspondientes a cada uno de los cuatro cantones que se utilizaron como marco muestral (marco de áreas) fueron las Unidades Primarias de Muestreo (UPM), que son "áreas geográficas en las que se divide cada distrito del país y que contienen en promedio 150 viviendas en la zona urbana y 100 viviendas en promedio en las zonas rurales" (INEC, 2014a, p. 83). Estas Unidades Primarias de Muestreo fueron obtenidas en el Instituto Nacional de Estadística y Censos (INEC).

\footnotetext{
${ }^{4}$ Se agradece la valiosa colaboración de la señora Ligia Bermúdez, profesional en estadística, quien labora en la Vicerrectoría de Investigación de la Universidad Estatal a Distancia (Costa Rica), asesoró en el diseño de la muestra y estuvo atenta a responder y orientar aspectos metodológicos de la investigación.
}

10 


\section{Cálculo y selección de la muestra}

Dado que los objetivos de la investigación estuvieron relacionados con la indagación de factores y opiniones que manifiestan las personas residentes en los cuatro cantones en estudio acerca de aspectos relacionados con la emigración, se aplicó la fórmula para la estimación de proporciones:

$$
n=\frac{N \sigma^{2} Z^{a 2}}{e^{2}(N-1)+\sigma^{2} Z^{a 2}}
$$

Donde:

$\mathrm{n}$ : tamaño de la muestra a seleccionar

$Z^{\mathrm{a}}$ : valor asociado al nivel de confianza de la muestra

$\sigma:$ desviación estándar de la proporción poblacional

e: error máximo aceptable en las estimaciones

Para el cálculo de las muestras fue asumida una proporción poblacional (P) del $70 \%$, ya que no se previó alta variabilidad entre las opiniones de los residentes en los cuatro cantones. Se calculó el tamaño mínimo correspondiente a un nivel de confianza del 95\% y un error máximo permisible del $5 \%$ entre el valor estimado y la verdadera proporción poblacional. El tamaño total de la muestra (325 hogares) se distribuyó entre los cuatro cantones, asumiéndolos como estratos. La distribución inicial se hizo aproximadamente proporcional al número de hogares por cantón, según puede observarse en la Tabla 2.

Para cada una de las encuestas el tamaño mínimo de muestra calculado era de 325 hogares. No obstante, se logró obtener un mayor número de encuestas efectivas para los hogares receptores y una cantidad menor en la encuesta a hogares con emigrantes potenciales: 358 y 301, respectivamente.

En el caso de los hogares con familiares en el extranjero fue posible obtener más encuestas efectivas por la información disponible (358 con un porcentaje obtenido de 110,2\%), ya que en los mapas estaban identificadas las áreas con mayor concentración de hogares que reciben remesas del exterior, de acuerdo con los resultados del último censo nacional. La situación contraria se dio en los hogares con emigrantes potenciales, para los cuales no había ninguna información previa (301 con un porcentaje obtenido de 93,5\%); es decir, no se contó con datos previos que indicaran quién emigrará. Para esta encuesta, el cálculo de la muestra asumió un comportamiento similar y en relación con los hogares con familiares en el extranjero.

Ambas muestras habían sido calculadas para obtener resultados con un nivel de confianza del $95 \%$ y un margen de error máximo permisible del $5 \%$ en las estimaciones $(e=0,05)$. Al considerar 
la cantidad de encuestas efectivas, se mantiene el nivel de confianza en las dos encuestas y solo se afecta levemente el margen de error. En la encuesta a hogares receptores el margen de error disminuye a $4,8 \%(e=0,048)$, ya que se logró una cantidad mayor a la prevista. Para la encuesta a hogares con emigrantes potenciales, el margen de error sube a $5,2 \%(e=0,052)$, debido al menor número de encuestas efectivas. En general, los porcentajes de cobertura son altos en ambos casos y la cantidad de encuestas es suficiente para garantizar la confiabilidad de los resultados ${ }^{5}$.

\section{Perfil sociodemográfico de las personas con expectativas de migrar}

Se entrevistó un total de 301 personas que expresaron su voluntad de emigrar; de ellas, 182 fueron hombres (60,47\%) y 119 fueron mujeres (39,53\%); 238 personas fueron entrevistadas en el cantón de Pérez Zeledón (79,07\%); 47 personas en Tarrazú (15,61\%); 10 personas en León Cortés $(3,32 \%)$; y 6 en Dora $(1,99)$. Del total de personas entrevistadas, aproximadamente el $81 \%$ es menor de 40 años; este porcentaje es levemente superior para este grupo etario en el cantón de Pérez Zeledón, donde se acerca al 85\%.

\section{Escolaridad según cantón de residencia de las personas entrevistadas}

La escolaridad reportada, según se observa en la Tabla 3, evidencia que, en el caso de la muestra de la investigación, casi dos terceras partes del total $(65,45 \%)$ tienen una baja escolaridad, que se verifica al sumar los porcentajes de primaria completa, primaria incompleta y secundaria incompleta.

Tabla 3.

Costa Rica: cantón de residencia y escolaridad de las personas entrevistadas que expresaron su intención de emigrar.

\begin{tabular}{l|rr|rr|rr|rr|rr}
\hline \multirow{2}{*}{ Escolaridad } & \multicolumn{1}{|c|}{ Cantón de residencia } & \multicolumn{3}{c}{ Totales } \\
\cline { 2 - 11 } & \multicolumn{2}{|c|}{ Dota } & \multicolumn{2}{|c|}{ Tarrazú } & \multicolumn{2}{c|}{ León Cortés } & Pérez Zeledón & Absoluto & Relativo \\
\hline Primaria completa & 3 & 50,00 & 12 & 25,53 & 1 & 10,00 & 54 & 22,69 & 70 & 23,26 \\
Primaria incompleta & 0 & 0,00 & 4 & 8,51 & 1 & 10,00 & 17 & 7,14 & 22 & 7,31 \\
Secundaria completa & 0 & 0,00 & 12 & 25,53 & 3 & 30,00 & 43 & 18,07 & 58 & 19,27 \\
Secundaria incompleta & 0 & 0,00 & 14 & 29,79 & 4 & 40,00 & 87 & 36,55 & 105 & 34,88 \\
Universidad completa & 1 & 16,67 & 4 & 8,51 & 0 & 0,00 & 2 &, 84 & 7 & 2,33 \\
Universidad incompleta & 2 & 33,33 & 1 & 2,13 & 1 & 10,00 & 35 & 14,71 & 39 & 12,96 \\
\hline Totales & $\mathbf{6}$ & $\mathbf{1 0 0}$ & $\mathbf{4 7}$ & $\mathbf{1 0 0 , 0 0}$ & $\mathbf{1 0}$ & $\mathbf{1 0 0 , 0 0}$ & $\mathbf{2 3 8}$ & $\mathbf{1 0 0 , 0 0}$ & $\mathbf{3 0 1}$ & $\mathbf{1 0 0 , 0 0}$ \\
\hline
\end{tabular}

Fuente: elaboración propia con datos de encuestas aplicadas.

${ }^{5}$ El trabajo de campo en los cuatro cantones en donde se aplicaron las encuestas se realizó del 23 al 27 de febrero y 02 al 06 de marzo del año 2015.

12 
El dato acerca de la escolaridad de las personas con expectativas de emigrar permite observar que la mitad de las personas entrevistadas tendría más dificultades de encontrar un empleo o, encontrándolo, sería poco calificado y con baja remuneración. El perfil educativo que presentan las personas entrevistadas puede dar lugar a una expulsión de trabajadores poco calificados.

\section{Principales motivaciones para dejar el país}

Tres son las motivaciones principales para emigrar que reportan las personas entrevistadas (Tabla 4), estas son, en orden de importancia: buscar mejores condiciones de vida (36,13\%), ahorrar y retornar $(30,25 \%)$, y buscar un empleo $(21,43 \%)$.

Tabla 4.

Costa Rica: cantones seleccionados. Motivos para emigrar reportados por las personas entrevistadas.

\begin{tabular}{|c|c|c|c|c|c|c|c|c|}
\hline \multirow{3}{*}{$\begin{array}{l}\text { Motivación mencionada } \\
\text { Búsqueda de empleo }\end{array}$} & \multicolumn{8}{|c|}{ Cantones } \\
\hline & \multicolumn{2}{|c|}{ Dota } & \multicolumn{2}{|c|}{ Tarrazú } & \multicolumn{2}{|c|}{ León Cortés } & \multicolumn{2}{|c|}{ Pérez Zeledón } \\
\hline & 2 & 33,33 & 12 & 25,53 & 1 & 10,00 & 51 & 21,43 \\
\hline Buscar mejores condiciones de vida & 1 & 16,67 & 24 & 51,06 & 5 & 50,00 & 86 & 36,13 \\
\hline Reunificación familiar & 0 & 0,00 & 2 & 4,26 & 0 & 0,00 & 12 & 5,04 \\
\hline Inestabilidad económica del país & 0 & 0,00 & 0 & 0,00 & 1 & 10,00 & 7 & 2,94 \\
\hline Ahorrar y retornar & 2 & 33,33 & 5 & 10,64 & 2 & 20,00 & 72 & 30,25 \\
\hline $\begin{array}{l}\text { Crear un negocio o fortalecer uno ya } \\
\text { existente }\end{array}$ & 0 & 0,00 & 2 & 4,26 & 0 & 0,00 & 8 & 3,36 \\
\hline Otra & 1 & 16,67 & 2 & 4,26 & 1 & 10,00 & 2 & 0,84 \\
\hline Totales & 6 & 100,00 & 47 & 100,00 & 10 & 100,00 & 238 & 100,00 \\
\hline
\end{tabular}

Fuente: elaboración propia con datos de encuestas aplicadas.

Las tres principales motivaciones, al agruparse, alcanzan un $88 \%$ del total, según se desprende de la Tabla 4. De acuerdo con la muestra, estas razones estarían configurando una migración marcadamente laboral. Por otra parte, como ya ha sido señalado, el perfil educativo de las personas entrevistadas reforzaría un panorama adverso para su inserción laboral en el país de destino.

\section{Perfil de los hogares que tienen familiares en el extranjero: género, edad y tenencia de la vivienda}

Para la segunda encuesta se entrevistó un total de 358 personas de hogares con familiares en el extranjero (esposo, esposa, hijos o hermanos). Del total de personas entrevistadas, 265 fueron mujeres (74,02\%) y 93 fueron hombres (25,98\%). Fueron aplicadas 227 encuestas en Pérez Zeledón (63,41\%), 81 en Tarrazú (22,63\%), 32 en Dota (8,94\%) y 18 en León Cortés (5,03\%). 
Respecto del perfil etario de las personas potenciales migrantes, la encuesta aplicada a hogares con familiares en el extranjero registró a 169 personas menores de 45 años (47\% de la muestra) y 189 personas mayores de 46 años (53\%).

Asimismo, según la información proporcionada por los hogares con familiares en el extranjero, una proporción superior al $80 \%$ tiene casa propia ( $\underline{\text { Tabla } 5}$ ).

Tabla 5.

Costa Rica: cantones seleccionados. Tenencia de la vivienda de los hogares entrevistados.

\begin{tabular}{|c|c|c|c|c|c|c|c|c|c|c|}
\hline \multirow[b]{2}{*}{ Tenencia } & \multicolumn{8}{|c|}{ Cantones } & \multicolumn{2}{|c|}{ Totales } \\
\hline & \multicolumn{2}{|c|}{ Dota } & \multicolumn{2}{|c|}{ Tarrazú } & \multicolumn{2}{|c|}{ León Cortés } & \multicolumn{2}{|c|}{ Pérez Zeledón } & $\begin{array}{c}\text { Absolut } \\
0\end{array}$ & Relativo \\
\hline Propia & 27 & 84,38 & 71 & 87,65 & 18 & 100,00 & 182 & 80,53 & 298 & 83,47 \\
\hline Alquilada & 2 & 6,25 & 3 & 3,70 & 0 & 0,00 & 29 & 12,83 & 34 & 9,52 \\
\hline Prestada & 2 & 6,25 & 6 & 7,41 & 0 & 0,00 & 14 & 6,19 & 22 & 6,16 \\
\hline Otra & 0 & 0,00 & 1 & 1,23 & 0 & 0,00 & 1 & 0,44 & 2 & 0,56 \\
\hline $\begin{array}{l}\text { No sabe/ no } \\
\text { responde }\end{array}$ & 1 & 3,13 & 0 & 0,00 & 0 & 0,00 & 0 & 0,00 & 1 & 0,28 \\
\hline Totales & 32 & 100,00 & 81 & 100,00 & & 100,00 & 226 & 100,00 & 357 & 100,00 \\
\hline
\end{tabular}

Fuente: elaboración propia con datos de encuestas aplicadas.

Por otra parte, el 65,53\% de los hogares entrevistados que reportaron tener vivienda propia reciben entre $\$ 20$ y $\$ 399$ por envío. Asimismo, 32 hogares $(8,94 \%)$ entrevistados afirmaron haber comprado alguna propiedad en el último año con los ingresos provenientes de las remesas familiares.

\section{Periodicidad con la que se reciben las remesas}

La periodicidad con la que reciben las remesas familiares los hogares entrevistados puede ser un indicador de la importancia de las personas migrantes como proveedores materiales de los hogares y del papel que juegan las remesas familiares para los hogares entrevistados (Tabla 6).

De acuerdo con la Tabla 6 , en el cantón de Dota un 34,39\% de los hogares reportaron recibir las remesas con una periodicidad igual o menor a un mes (mensual). En Tarrazú esta periodicidad es de $43,21 \%$, en León Cortés es levemente superior $(44,44 \%)$, mientras que en Pérez Zeledón alcanza el $58,1 \%$. Por cantidad de miembros del hogar y tractos de ingresos, algunos datos son los siguientes: el $27,27 \%$ de los hogares que reciben entre $\$ 200$ y $\$ 299$ tiene cinco miembros; el $36,84 \%$ de los hogares que reciben entre $\$ 400$ y $\$ 499$ tiene cuatro miembros y el $39,62 \%$ de los hogares que reciben entre $\$ 500$ y $\$ 749$ tiene tres miembros. Es decir, entre menos miembros, más dinero se recibe.

14 
Tabla 6.

Costa Rica: cantones seleccionados. Periodicidad con la que reciben remesas.

\begin{tabular}{|c|c|c|c|c|c|c|c|c|c|c|}
\hline \multirow{2}{*}{ Periodicidad } & \multicolumn{8}{|c|}{ Cantones } & \multicolumn{2}{|c|}{ Totales } \\
\hline & \multicolumn{2}{|c|}{ Dota } & \multicolumn{2}{|c|}{ Tarrazú } & \multicolumn{2}{|c|}{ León Cortés } & \multicolumn{2}{|c|}{ Pérez Zeledón } & Absoluto & Relativo \\
\hline Cada semana & 1 & 3,13 & 2 & 2,47 & 0 & 0,00 & 10 & 4,41 & 13 & 3,63 \\
\hline Cada quince días & 1 & 3,13 & 3 & 3,70 & 2 & 11,11 & 26 & 11,45 & 32 & 8,94 \\
\hline Cada mes & 9 & 28,13 & 30 & 37,04 & 6 & 33,33 & 118 & 51,98 & 163 & 45,53 \\
\hline Cada dos meses & 3 & 9,38 & 10 & 12,35 & 1 & 5,56 & 19 & 8,37 & 33 & 9,22 \\
\hline Cada tres meses & 7 & 21,88 & 6 & 7,41 & 0 & 0,00 & 17 & 7,49 & 30 & 8,38 \\
\hline Cada cuatro meses & 4 & 12,50 & 16 & 19,75 & 5 & 27,78 & 12 & 5,29 & 37 & 10,34 \\
\hline Cada año & 5 & 15,63 & 7 & 8,64 & 4 & 22,22 & 12 & 5,29 & 28 & 7,82 \\
\hline Ocasionalmente & 2 & 6,25 & 7 & 8,64 & 0 & 0,00 & 13 & 5,73 & 22 & 6,15 \\
\hline Totales & 32 & 100,00 & 81 & 100,00 & 18 & 100,00 & 227 & 100,00 & 358 & 100,00 \\
\hline
\end{tabular}

Fuente: elaboración propia con datos de encuestas aplicadas.

\section{Ingreso por tractos reportados por los hogares y recepción de remesas familiares}

De las 358 encuestas realizadas, 258 hogares brindaron información acerca del ingreso autónomo; es decir, del ingreso que perciben aparte de las remesas familiares (Tabla 7). Este dato permite ver cuánto le suma el ingreso de la remesa familiar al ingreso corriente del hogar.

Tabla 7

Costa Rica: Ingreso de los hogares sin remesas y montos que reportan recibir los hogares.

\begin{tabular}{|c|c|c|c|c|c|c|c|c|c|c|c|c|c|c|}
\hline \multirow{3}{*}{$\begin{array}{l}\text { Monto } \\
20 \text { y } \$ 99\end{array}$} & \multicolumn{14}{|c|}{ Ingreso de los hogares por tractos según monto de remesas familiares recibidas } \\
\hline & \multicolumn{2}{|c|}{$\begin{array}{c}\text { C } 0- \\
\text { c199.000 }\end{array}$} & \multicolumn{2}{|c|}{$\begin{array}{c}\text { ¿200.000 - } \\
\text { ¿299.000 }\end{array}$} & \multicolumn{2}{|c|}{$\begin{array}{l}\$ 300.000- \\
\$ 399.000\end{array}$} & \multicolumn{2}{|c|}{$\begin{array}{c}\$ 400.000- \\
\$ 499.000\end{array}$} & \multicolumn{2}{|c|}{$\begin{array}{c}\text { C500.000 - } \\
\text { C749.000 }\end{array}$} & \multicolumn{2}{|c|}{$\begin{array}{l}\text { Más de } \\
\text { C749.000 }\end{array}$} & \multicolumn{2}{|c|}{$\begin{array}{l}\text { Total, hogares } \\
\text { que informaron } \\
\text { sobre ingreso } \\
\text { sin remesas }\end{array}$} \\
\hline & 12,0 & 50,0 & 7,0 & 29,2 & 4,0 & 16,7 & 0,0 & 0,0 & 1,0 & 4,2 & 0,0 & 0,0 & 24,0 & 100,0 \\
\hline Entre $\$ 100$ y $\$ 199$ & 42,0 & 53,2 & 19,0 & 24,1 & 11,0 & 13,9 & 2,0 & 2,5 & 4,0 & 5,1 & 1,0 & 1,3 & 79,0 & 100,0 \\
\hline Entre $\$ 200$ y $\$ 299$ & 31,0 & 53,4 & 10,0 & 17,2 & 11,0 & 19,0 & 4,0 & 6,9 & 2,0 & 3,4 & 0,0 & 0,0 & 58,0 & 100,0 \\
\hline Entre $\$ 300$ y $\$ 399$ & 10,0 & 38,5 & 12,0 & 46,2 & 2,0 & 7,7 & 1,0 & 3,8 & 1,0 & 3,8 & 0,0 & 0,0 & 26,0 & 100,0 \\
\hline Entre $\$ 400$ y $\$ 499$ & 10,0 & 71,4 & 2,0 & 14,3 & 1,0 & 7,1 & 0,0 & 0,0 & 1,0 & 7,1 & 0,0 & 0,0 & 14,0 & 100,0 \\
\hline Entre $\$ 500$ y $\$ 749$ & 15,0 & 42,9 & 8,0 & 22,9 & 6,0 & 17,1 & 1,0 & 2,9 & 3,0 & 8,6 & 2,0 & 5,7 & 35,0 & 100,0 \\
\hline Entre \$ 750 y \$ 999 & 2,0 & 66,7 & 1,0 & 33,3 & 0,0 & 0,0 & 0,0 & 0,0 & 0,0 & 0,0 & 0,0 & 0,0 & 3,0 & 100,0 \\
\hline Entre $\$ 1,000$ y $\$ 2,000$ & 4,0 & 21,1 & 2,0 & 10,5 & 2,0 & 10,5 & 2,0 & 10,5 & 6,0 & 31,6 & 3,0 & 15,8 & 19,0 & 100,0 \\
\hline Más de $\$ 2,000$ & 0,0 & 0,0 & 0,0 & 0,0 & 0,0 & 0,0 & 0,0 & 0,0 & 0,0 & 0,0 & 0,0 & 0,0 & 0,0 & 0,0 \\
\hline Totales & 126,0 & 48,8 & 61,0 & 23,6 & 37,0 & 14,3 & 10,0 & 3,9 & 18,0 & 7,0 & 6,0 & 2,3 & 258,0 & 100,0 \\
\hline
\end{tabular}

Fuente: elaboración propia con datos de encuestas aplicadas.

Los hogares que reportaron información de sus ingresos en una cuantía menor a \$199.000 representan casi el $50 \%$ del total de hogares informantes del ingreso autónomo a las remesas familiares. Para este grupo de hogares, el ingreso proveniente de estas transferencias se convierte en un ingreso fundamental que incrementa sus limitados ingresos autónomos. 
Según cálculos de la Encuesta Nacional de Hogares (ENAHO) del año 2014a, del Instituto Nacional de Estadísticas y Censos (INEC), el grupo de hogares que pertenecen al primer quintil de ingresos para el año 2014 registra un ingreso neto (sin remesas familiares) de $\$ 198.540$ y un ingreso per cápita (por cada miembro del hogar) de \$54.021. El ingreso neto por hogar de los hogares de la encuesta realizada está muy por debajo de los ingresos promedio neto para la Región Brunca reportados por la ENAHO (2014a), que corresponde a $\mathbf{6 7 1 . 4 6 5 . ~ E n ~ t a n t o ~ q u e ~ e l ~ i n g r e s o ~ p r o m e d i o ~}$ de los hogares del primer quintil es de \$129.631 mensuales, en esta misma región.

Medida la condición de pobreza por el nivel de ingresos y utilizando la metodología de la Línea de Pobreza, en la región Brunca la incidencia de la pobreza en los hogares afectó a 36,2\% de estos en el año 2014 (INEC 2014a). La información de la ENAHO indica que para el año 2014, el ingreso promedio de los hogares en condición de pobreza (no extrema), utilizando la metodología señalada, fue de $\$ 270.868$, siendo el ingreso de los hogares pobres del área urbana de \$291.807 y de los hogares en condición de pobreza del área rural de \$229.532. Estos datos indicarían que al menos el $48,84 \%$ de los hogares entrevistados se encuentra por debajo de la línea de pobreza.

Dos datos resultan de interés: el 39,9\% de los hogares entrevistados recibe periódicamente remesas en montos iguales o menores a \$199; por otra parte, 54 hogares indicaron que su ingreso autónomo sin remesas era menor a \$199.000 y que recibían montos periódicos por remesas familiares iguales o menores a \$199 (Tabla 7). Para aproximadamente 2 de cada 10 hogares que tienen un ingreso autónomo mensual igual o menor a \$199.000, las remesas familiares que reciben les permiten desplazarse del primer al segundo quintil de ingresos y superar al mismo tiempo la línea de pobreza.

De acuerdo con la muestra y en términos absolutos, ello significa que un total de 839 hogares, de un total de 4.012 hogares con miembros en el extranjero de los cuatro cantones, ven incrementados sus ingresos y superan la línea de la pobreza. Por otra parte, las remesas familiares enviadas por los costarricenses en el exterior oriundos de estos cantones estarían permitiendo una reducción de la pobreza del 1,71\% del total de hogares en los cantones de estudio.

Por otra parte, ¿cuál es la estructura de la utilización de los recursos que hacen los hogares receptores de remesas familiares entrevistados? La Tabla 8 presenta una distribución según la información brindada por los hogares entrevistados.

16 
Tabla 8.

Costa Rica: cantones seleccionados. Estructura porcentual de la utilización de las remesas.

\begin{tabular}{lc}
\hline \multicolumn{1}{c}{ Rubro } & Asignación \\
\hline Alimentación & 46,37 \\
Educación & 8,38 \\
Gastos de salud & 9,22 \\
Pago de deudas e hipotecas & 9,50 \\
Pago de servicios públicos & 9,50 \\
Inversión en negocio propio & 4,75 \\
Construcción & 4,19 \\
Compra de otros bienes & 3,35 \\
Recreación & 1,40 \\
Ahorro & 3,35 \\
\hline Totales & $\mathbf{1 0 0 , 0 0}$ \\
\hline
\end{tabular}

Fuente: elaboración de propia con datos de encuestas aplicadas.

Así pues, según la información proporcionada por los hogares entrevistados, aproximadamente la mitad de los ingresos provenientes de las remesas familiares se utiliza para gastos de alimentación.

Tomando como base la información disponible (ingresos reportados por los hogares entrevistados) se calculó el índice de Gini, según la fórmula usual (Anexo 1). De los hogares entrevistados, 258 ofrecieron información sobre los ingresos que perciben mensualmente con y sin remesas. Para estos hogares se calcularon dos Gini, uno para la distribución de los ingresos sin remesas familiares y un segundo con el escenario de las remesas familiares formando parte del total de los ingresos.

Para el cálculo del coeficiente de Gini con la introducción de la variable "con remesas", se agrupó los hogares por quintiles de ingresos, teniendo a la vista los datos registrados por la Encuesta de Hogares 2014 del INEC. El coeficiente de Gini para los hogares antes de la recepción de las remesas fue de 0,29 mientras que, con la recepción de las remesas, el coeficiente fue de 0,22, lo cual indica que existe una mejora en la distribución de los ingresos en los hogares receptores de remesas.

\section{Conclusiones}

Hoy día, al interior de una economía como la costarricense, la heterogeneidad productiva y ocupacional existe y se enmarca dentro de una dinámica mucho más poderosa, y es la forma en la que el país se integra a la economía global a la que suministra, según sea el caso: manufactura tecnológica, manufactura industrial, bienes agrícolas procesados, materia prima agrícola o, más recientemente, fuerza de trabajo. Esta integración, a pesar de intentar diversificarse, no deja de 
ser una incorporación de país periférico a los países centrales, que tiene, como rasgo característico, la desigualdad y asimetría.

Estas dinámicas y transformaciones, además de impactar en la matriz productiva y de empleo, contribuyeron a acentuar asimetrías regionales y territoriales. La promoción de núcleos industriales y de servicios se ha concentrado prioritariamente en el Valle Central de Costa Rica, desvinculando las estrategias de promoción de estas actividades del resto de regiones del país. Los cantones de la Zona de Los Santos y Pérez Zeledón pueden ser ejemplo de territorios que quedaron al margen de estos procesos de transformación, anclados a las actividades del sector primario, con esfuerzos notables por dar mayor valor agregado a la producción agrícola.

En la primera parte de este trabajo se presentó una síntesis de la crítica a los enfoques que interpretan de manera mecánica las migraciones, los cuales insisten en que las remesas familiares contribuyen al desarrollo. Los resultados del trabajo de campo mostraron que, en el caso de los cantones en estudio, las remesas familiares se convierten en un paliativo que incrementa los ingresos de los hogares receptores. De estos ingresos, tres cuartas partes se destinan a gastos de consumo y solo una pequeña fracción (menos del $5 \%$ ) se invierte en un negocio propio. Este dato es cercano al registrado por el Banco Central de Costa Rica, respecto del porcentaje de las remesas familiares que invierten los hogares receptores costarricenses para negocios, que es apenas el 3\% (BCCR, 2015).

Así las cosas, no se podría decir, a partir de estos datos, que en los cantones en estudio las remesas familiares sean una notable contribución al desarrollo. En cambio, debe reconocerse que operan como una transferencia económica, la cual aminora los ya deteriorados datos de pobreza en la región. Paradójicamente, aquellos trabajadores que fueron expulsados por los cambios y transformaciones de la economía costarricense hacen un aporte silencioso pero fundamental a la economía de los hogares receptores que, en ausencia de estos ingresos, verían incrementada su condición de vulnerabilidad económica.

Tradicionalmente, el país se ha visto a sí mismo como receptor de población migrante; ello ha ha contribuido a invisibilizar la expulsión de personas. La información recopilada en el trabajo de campo permite obtener una actualización tanto de las características de los hogares que tienen familiares en el extranjero, como de las personas para quienes la experiencia migratoria se presenta como una opción y están considerando la decisión de emigrar.

Por otra parte, las migraciones internacionales desde Costa Rica tienen un doble impacto. En primer lugar, a nivel macroeconómico el país cuenta con un flujo estable y permanente de divisas que ya registra la balanza de pagos del Banco Central. En segundo lugar, se ha comprobado que las remesas familiares hacen un aporte a los ingresos fiscales, según las estimaciones realizadas.

18

Gustavo Gatica López

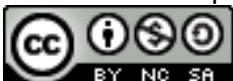

Revista Economía y Sociedad by Universidad Nacional is licensed under a CreativeCommons Reconocimiento-NoComercial- 


\section{Referencias}

Amin, S. (1981). La acumulación a escala mundial ( $5^{\text {ta }}$ ed. en español). Recuperado de http://www.sigloxxieditores.com/libros/La-acumulaciOn-a-escalamundial/9788432301612

Appleyard D. y Field A. (2003). Economía Internacional (4 ${ }^{\text {ta }}$ ed.). Recuperado de https://books.google.co.cr/books/about/Econom\%C3\%ADa internacional.html?id=X 9KZQWAACAAJ\&redir esc $=y$

Banco Central de Costa Rica (2015). Aspectos socioeconómicos de las remesas familiares 2014. Recuperado http://www.bccr.fi.cr/publicaciones/politica_cambiaria sector externo/Aspectos S ocioeconomicos de las Remesas Familiares 2014.pdf

Banco Central de Costa Rica (2017a). Inversión directa: Conciliación entre el principio activo/pasivo y el principio direccional. Recuperado de http://indicadoreseconomicos.bccr.fi.cr/indicadoreseconomicos/Cuadros/frmVerCat Cuadro.aspx?CodCuadro=3738\&Idioma $=1 \&$ FecInicial $=2000 / 03 / 31 \&$ FecFinal $=2016 / 0$ 9/30\&Filtro=0\&Jump $=4$

Banco Central de Costa Rica (2017b). Balanza de pagos trimestral. Recuperado de http://indicadoreseconomicos.bccr.fi.cr/indicadoreseconomicos/Cuadros/frmVerCat Cuadro.aspx?CodCuadro=2463\&Idioma $=1 \&$ Feclnicial $=2000 / 01 / 01 \&$ FecFinal $=2016 / 0$ 9/30\&Filtro=0\&Jump $=3$

Castles, S. (2005). Nation and Empire: Hierarchies of Citizenship in the New Global Order. Recuperado de: https://www.researchgate.net/publication/233678077 Nation and Empire Hierarc hies of Citizenship in the New Global Order

Céspedes-Torres O., Monge-González R. y Vargas-Aguilar J. (2010). Análisis de un corredor de remesas norte-sur en los contextos norte-sur y sur-sur: Estados Unidos-Costa Rica. Recuperado de https://publications.iadb.org/handle/11319/5379

Delgado, R. y Márquez, H. (2007). Teoría y práctica de la relación dialéctica entre desarrollo y migración. Migración y Desarrollo, (9), 5-25. Recuperado de http://rimd.reduaz.mx/revista/rev9/c1.pdf 
Delgado, R., Márquez, H. y Rodríguez, H. (2009). Seis tesis para desmitificar el nexo entre migración y desarrollo. Migración y Desarrollo, (12), 27-52. Recuperado de http://www.scielo.org.mx/scielo.php?script=sci arttext\&pid=S1870$\underline{75992009000100002}$

Gudynas, E. (2012). Debates sobre el desarrollo y sus alternativas en América Latina: Una breve guía heterodoxa. En Lang, M. y Mokrati, D (comps.). Más allá del desarrollo (21-55). Recuperado de http://rosalux.org.mx/docs/Mas alla del desarrollo.pdf

Instituto Nacional de Estadística y Censos (2012). X Censo Nacional de Población y VI de Vivienda. Resultados Generales. Recuperado de: http://www.inec.go.cr/publicaciones?fuente tid=157

Instituto Nacional de Estadística y Censos (2014a). Encuesta Nacional de Hogares 2014: Resultados generales. Recuperado de http://www.inec.go.cr/buscador?buscar=Encuesta+Nacional+de+Hogares+2014+Res ultados+generales

Instituto Nacional de Estadística y Censos (2014b). Encuesta Nacional de Ingresos y Gastos de los Hogares 2013. Principales resultados. Recuperado de: http://www.inec.go.cr/publicaciones?fuente tid=139.

Márquez, H. (2010). Desarrollo y migración: una lectura desde la economía política crítica. Migración y Desarrollo, 8(14), 59-87. Recuperado de http://www.scielo.org.mx/pdf/myd/v8n14/v8n14a4.pdf

Márquez, H. y Delgado, R. (2012). Espejismos del Río de Oro. Dialéctica de la migración y el desarrollo en México. Recuperado de https://books.google.co.cr/books/about/Espejismos del r\%C3\%ADo de oro.html?i $\mathrm{d}=5$ W6VmWEACAAJ\&redir esc $=\mathrm{y}$

Ministerio de Hacienda (2014). El gasto tributario, metodología y estimación, año 2013. San José, Costa Rica: Ministerio de Hacienda.

Orozco, M. (2012). América Latina y el Caribe: desarrollo, migración y remesas. Recuperado https://www.amazon.com/Am\%C3\%A9rica-Latina-Caribe-Desarrollomigraci\%C3\%B3n/dp/9871867239 
Orozco, M. y Yansura, J. (2013). Migración y Desarrollo en América Central: Percepciones, Políticas y Nuevas Oportunidades (documento de trabajo). Recuperado del Inter-American Development Bank: http://www19.iadb.org/intal/intalcdi/PE/2014/13560.pdf

Piketty, T. (2014). El capital en el siglo XXI. Recuperado de https://www.casadellibro.com/libroel-capital-en-el-siglo-xxi/9788437507231/2396221

Ray, D. (2002). Economía del desarrollo. Recuperado de http://www.antonibosch.com/libros?utf8=\%E2\%9C\%93\&muestra=libros\&buscar=EC onom\%C3\%ADa+del+desarrollo\&submit. $x=0 \&$ submit. $y=0$

Rodríguez, O. (1984). La teoría del subdesarrollo de la CEPAL. Recuperado de https://books.google.es/books/about/La teor\%C3\%ADa del_subdesarrollo de la CEPAL.html?id=86M7ttEtGTUC

Rodríguez, O. (1998). Heterogeneidad estructural y empleo. Revista de la CEPAL Número extraordinario, 315-321. Recuperado de http://repositorio.cepal.org/bitstream/handle/11362/12147/0NE315321 es.pdf?se quence $=1$

Sassen, S. (2003). Contrageografías de la globalización género y ciudadanía en los circuitos transfronterizos. Recuperado de http://www.acuedi.org/ddata/9217.pdf

Todaro, M. (1969). A model of labor migration and urban unemployment in less developed countries. The American Economic Review, 59(1). 138-148. Recuperado de http://www.cec.zju.edu.cn/ yao/uploadfile/papers/p014.pdf

Wallerstein, I. (2006). Análisis de Sistemas-Mundo: una introducción. Recuperado de https://books.google.co.cr/books/about/An\%C3\%A1lisis de sistemas mundo.html? id=Ipmi0DO6IOIC\&redir esc $=y$. 


\section{Anexo 1}

\section{Método utilizado para el cálculo del coeficiente de Gini}

Tomando como base la información disponible de ingresos reportados por los 258 hogares entrevistados se calcularon dos Gini, uno para la distribución de los ingresos sin remesas familiares y un segundo con el escenario de las remesas familiares formando parte del total de los ingresos. La fórmula utilizada para el cálculo fue la siguiente:

$$
C G=\frac{\sum_{i=1}^{n-1}\left(P_{i}-Y_{i}\right)}{\sum_{i=1}^{n-1} P_{i}}
$$

Donde

$P_{i}$ es la proporción acumulada de los hogares para cada nivel de ingreso

$Y_{i}$ es la proporción para cada nivel de ingreso de los hogares respecto del total de los ingresos totales

\section{2}

